Article

\title{
Research on the Roof Advanced Breaking Position and Influences of Large Mining Height Working Face in Shallow Coal Seam
}

\author{
Qingxiang Huang ${ }^{1,2, * \mathbb{C}}$, Yanpeng $\mathrm{He}^{1,2, * \mathbb{D}}$ and $\mathrm{Feng} \mathrm{Li}^{1,2}$ \\ 1 School of Energy Engineering, Xi'an University of Science and Technology, Xi'an 710054, China; \\ lifeng@stu.xust.edu.cn \\ 2 Key Laboratory of Western Mine Exploitation and Hazard Prevention, Ministry of Education, Xi'an \\ University of Science and Technology, Xi'an 710054, China \\ * Correspondence: huangqx@xust.sn.cn (Q.H.); heyp@stu.xust.edu.cn (Y.H.); Tel.: +86-029-8558-3143 (Q.H.)
}

Received: 17 March 2020; Accepted: 28 March 2020; Published: 3 April 2020

\begin{abstract}
The large mining height (LMH) in shallow coal seam has been widely applied in the Shenfu coalfield, China. The dynamic load is obvious, and the rib spalling is serious when the LMH working face concerns roof weighting. The advanced breaking position of the roof affects the strength of the ground pressure when the roof is broken. Firstly, based on a large number of actual measurements and physical simulation experiments, the rock formation in the fall zone, where the articulated structure cannot be articulated between the coal seam and the main roof, is called the equivalent immediate roof (EIR). When the mining height increases, the thickness of the EIR increases non-linearly. Next, based on the theory of "elastic foundation beam", a mechanical model for the advanced breaking of the roof is established in shallow coal seam, and the calculation equation for the advanced breaking position of the roof is given; then, designed and carry out boreholes of the no. 22201 working face in the Zhangjiamao Coal Mine. The theoretical calculation of key strata results $(5.6-6.9 \mathrm{~m})$ are in the range of field measurement results $(5-8 \mathrm{~m})$. According to the field measurement results, the roof movement of the LMH working face is ahead of the roof weighting. Finally, we define the thickness of EIR and the mining height ratio as the immediate mining ratio $k_{i}$, which affects the degree of filling of the goaf and determines the structural form of the main roof. When the $k_{i}$ is small, the goaf is fully filled; when the $k_{i}$ is large, the goaf is fully filled. Under the same conditions, different filling rate conditions will form different roof structures. Results of this research can be helpful to control roof weighting and provide early warning of possible safety problems related to the LMH working face in shallow coal seam.
\end{abstract}

Keywords: shallow coal seam; large mining height; advanced breaking; elastic foundation beam; time and space relationship; filing rate

\section{Introduction}

Shenfu-Dongsheng coalfield in China is one of the eight largest coalfields in the world. The main shallow coal seam in this area is Jurassic in age. The thickness of coal seam mining is $3.5-8 \mathrm{~m}$. Most of the working faces adopt the mining method of LMH and full mining height $[1,2]$. The roof structure will show the different strength of ground pressures before and after the fracture [3-7]. The roof fracture intervals depend on different boundary conditions. The fracture position and rotation angle of the main roof will affect the stability of the roof $[8,9]$. The structural model of roof breaking was established in shallow coal seam $[10,11]$. Meanwhile, as the mining height increases, mining directly affects the ground surface [12]. During the period of incoming weighting, there are obvious steps sinking, dynamic load, and serious phenomenon of rib spalling [13-18]. Based on a large number of 
field measurement analyses, the evolution characteristics of the roof structure at 4-7 $\mathrm{m} \mathrm{LMH} \mathrm{working}$ faces are analyzed. This, combined with the physical simulation and numerical calculation, the mechanism of the upward movement of the hinge point of the roof structure (caused by the increase of the roof thickness) and the definition of the equivalent immediate roof (EIR) of the large mining height working face is proposed [19-21]. The immediate roof of the high mining height is divided into three types, and the roof control mechanical model of the stope is given [22,23]. Based on the characteristics of the underground pressure at no. 22303 working face in the Bulianta coal mine, a structure model of the main roof cantilever beam with a $7.0 \mathrm{~m} \mathrm{LMH}$ was proposed [24-26]. A short cantilever beam-hinged rock beam structure of a fully mechanized mining roof with a large mining height is proposed to determine the working resistance of the support [27]. Other scholars have also studied the roof structure of the LMH stope [28-32]. However, there are few studies on the roof advanced breaking position of LMH working face in shallow coal seam.

In this paper, the research background concerns the 22201 working face in the Zhangjiamao Coal Mine in China, adopting a combination of theoretical analyses and field measurement methods to research on the advanced breaking position of the shallow-buried and high-mining working face. The present research is aimed at providing the basis for stable roof structure and optimize the choice of stope support and roadway advanced support methods.

\section{Establishment of the Mechanical Model of the Roof Advanced Breaking Position}

\subsection{Proposition of EIR}

Based on a large number of field measurements and physical simulation experiments of shallow buried and LMH working faces, authors [19-21] found that, as the mining height increases, some of the overlying strata that originally belonged to the geological main roof also caved. This phenomenon presents the function of immediate roof. Therefore, we propose that all rock layers that do not form a hinged structure between the main roof hinge layer and the coal seam are called "EIR". During normal mining, the geological immediate roof caves followed by excavating, and the lower part of the geological main roof is cantilever state. According to the statistics of EIR with 4-7 m different high-mining working faces in five typical coal mines in the Yushenfu mining area, the results are shown in Table 1. As the mining height increases, the thickness of EIR and $k_{i}\left(k_{i}\right.$ is the thickness of EIR and the mining height ratio as the immediate mining ratio) increase non- linearly, as shown in Figure 1.

Table 1. Equivalent immediate roof thickness of large mining height faces.

\begin{tabular}{cccccc}
\hline $\begin{array}{c}\text { Working Face of Coal } \\
\text { Mine }\end{array}$ & $\begin{array}{c}\text { Mining Height } \\
(\mathbf{m})\end{array}$ & $\begin{array}{c}\text { Period Weighting } \\
\text { Intervals (m) }\end{array}$ & $\begin{array}{c}\text { Thickness of } \\
\text { Key Strata (m) }\end{array}$ & $\begin{array}{c}\text { Thickness of } \\
\text { EIR (m) }\end{array}$ & $k_{i}$ \\
\hline $\begin{array}{c}\text { 31301 working face of } \\
\text { Wanli coal mine }\end{array}$ & 4.9 & 17.6 & 5.6 & 11.2 & 2.29 \\
\hline $\begin{array}{c}\text { 22406 working face of } \\
\text { Halagou coal mine }\end{array}$ & 5.2 & 12.1 & 10.3 & 13.1 & 2.52 \\
\hline $\begin{array}{c}\text { 22201 working face of } \\
\text { Zhangjiamao coal mine }\end{array}$ & 6.0 & 13.0 & 14 & 17 & 2.83 \\
\hline $\begin{array}{c}\text { 15201 working face of } \\
\text { Zhangjiamao coal mine }\end{array}$ & 6.2 & 15.6 & 9.5 & 16.2 & 2.61 \\
\hline $\begin{array}{c}85201 \text { working face of } \\
\text { Sandaogou coal mine }\end{array}$ & 6.5 & 24.2 & 10.3 & 16.8 & 2.58 \\
\hline $\begin{array}{c}\text { 22303 working face of } \\
\text { Bulianta coal mine }\end{array}$ & 6.8 & 11.0 & 9.4 & 18.2 & 2.67 \\
\hline $\begin{array}{c}52303 \text { working face of } \\
\text { Daliuta coal mine }\end{array}$ & 6.9 & 16.8 & 12.0 & 20.6 & 2.98 \\
\hline
\end{tabular}




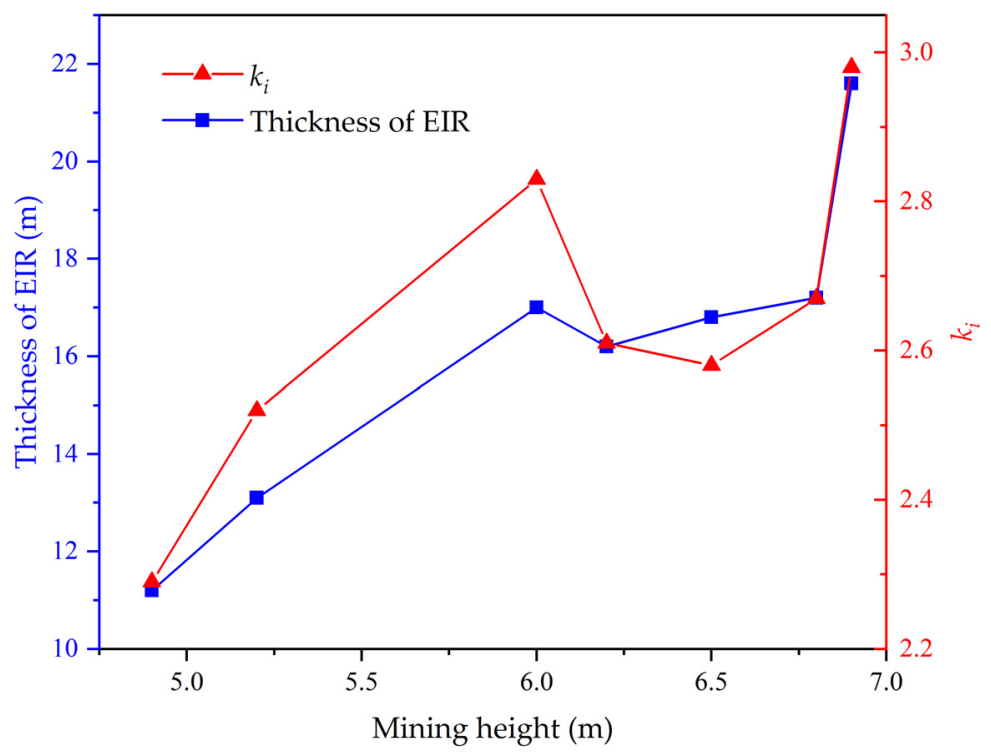

Figure 1. Diagram (Mining heights vs. EIR thickness) showing that the thickness of the EIR and $k_{i}$ varies with different mining heights.

Using the single variable method, we change the mining height on the same $5 \mathrm{~m}$ physical model experimental platform [16], in order to obtain the thickness of EIR at different mining heights. The results are shown in Figure 2. According to the Figures 1 and 2, we found that the thickness of EIR showed an increasing trend with the increase of the mining height, which caused the horizon of the main roof hinge structure rise; the caved roof filled the goaf area differently, which caused the different hinged structures in the overlying strata $[19,20]$. Many authors have proposed different roof structure models based on different mining geological conditions [29,30].

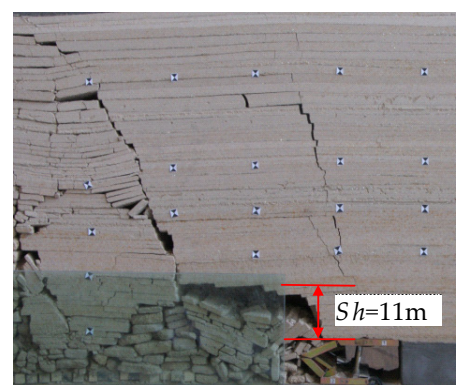

(a)

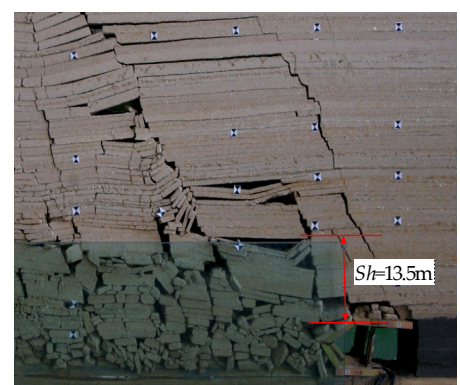

(b)

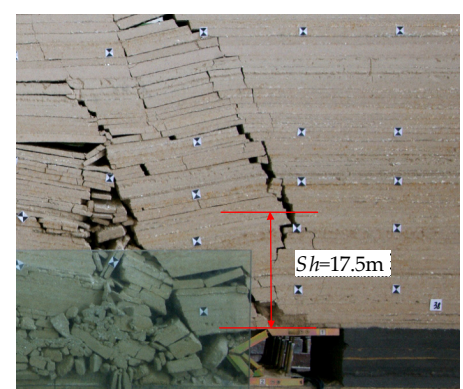

(c)

Figure 2. Pictures showing the thickness of EIR with different mining heights: (a) the mining height is $4 \mathrm{~m}$; (b) the mining height is $5 \mathrm{~m}$; (c) the mining height is $6 \mathrm{~m}$.

\subsection{Mechanical Model of Key Stratum Advanced Breaking Position}

The research found that when mining in shallow-buried and LMH working faces, the first and periodic breaks are all one-time full-thick breaks, the ground pressure appeared severely, the surface has obvious step sinking [1]. The structural effect of the roof was revealed, and the law of load transfer in thick loose layer of overburden is proposed [33-35]. The roof periodic breaking of the LMH working face in shallow coal seam can be divided into three stages: (1) advanced cracks appear ahead of the working face; (2) advanced cracks continue to expand; (3) the working face advances to the position of the advanced crack nearly, the roof sinks and forms a hinge structure.

The advanced breaking mechanics model of the key strata is established, as shown in Figure 3. The broken interval of the roof strata is mainly composed of the rock beam overhang length $L$ and the advanced breaking distance $x$. The bending moment $\left(M_{0}\right)$ and shear stress $\left(Q_{0}\right)$ of key strata above the 
coal wall in working face. The mining height of coal seam $(M)$ and the height of EIR $(\Sigma h)$ as elastic foundations, the roof strata as a beam located on the elastic foundation. The support effect is offset by balancing the weight of the EIR. The broken interval is $l$, the overhanging section of the roof strata on the elastic foundation is reduced to $R=0.5 q l$ by the force of the key strata, the overlying rock force is regarded as the uniformly distributed load $q$.

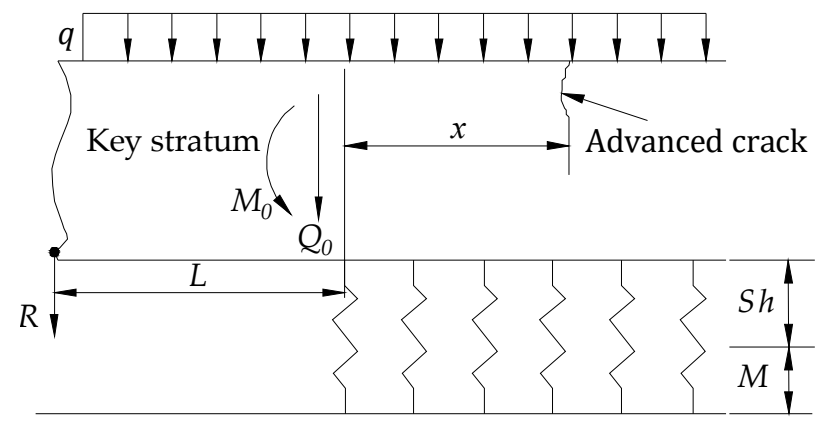

Figure 3. Mechanical model of periodic breaking of key stratum.

For the key stratum beam of unit width, the constitutive equation is:

$$
E I \frac{d^{4} y}{d x^{4}}+p(x)=q(x)
$$

where $E$ is the elastic modulus of the rock stratum of the main roof, $\mathrm{MPa}$; $I$ is the moment of inertia of the key stratum of roof, $\mathrm{m}^{4} ; y$ is the vertical displacement of the beam, $\mathrm{m} ; q(x)$ is the load of overlying strata on the key stratum beam of roof, $\mathrm{MPa} ; p(x)$ is the force of the lower stratum on the roof key stratum, MN.

According to the elastic foundation beam theory, there are:

$$
p(\mathrm{x})=k y
$$

where $k$ is the EIR and coal seam elastic foundation coefficient, $\mathrm{MN} / \mathrm{m}^{3}$.

According to Figure 3, the elastic foundation coefficient of the key stratum of the roof in the LMH working face is:

$$
k=\frac{E_{1} E_{m}}{E_{1} M+E_{m} \Sigma h}
$$

where $M$ is the mining height, $\mathrm{m} ; E_{\mathrm{m}}$ is the elastic modulus of the coal seam, $\mathrm{MPa} ; \Sigma h$ is the thickness of EIR, $\mathrm{m} ; E_{1}$ is the elastic modulus of EIR, MPa.

Then, the constitutive equation of the rock beam in the key stratum of the roof can be transformed into:

$$
E I \frac{d^{4} y}{d x^{4}}+k y=q(x)
$$

When the $\alpha=\sqrt[4]{\frac{k}{4 E I}}$, the general solution of Equation (1) is:

$$
y=e^{-\alpha x}\left[C_{1} \sin (\alpha x)+C_{2} \cos (\alpha x)\right]+e^{\alpha x}\left[C_{3} \sin (\alpha x)+C_{4} \cos (\alpha x)\right]+\frac{q}{k}
$$

In Equation (4), the undetermined coefficients $C_{1}, C_{2}, C_{3}$, and $C_{4}$ can be determined according to the boundary conditions. When the $x \rightarrow \infty, e^{-a x} \rightarrow 0, e^{a x} \rightarrow \infty$, so the $C_{3}=C_{4}=0$, substituting the coefficient into the above equation can be obtained:

$$
y=e^{-\alpha x}\left[C_{1} \sin (\alpha x)+C_{2} \cos (\alpha x)\right]
$$


Calculating Equation (5), the results are:

$$
\begin{gathered}
\frac{d y}{d x}=-\alpha e^{-\alpha x}\left[\left(C_{1}+C_{2}\right) \sin (\alpha x)+\left(C_{2}-C_{3}\right) \cos (\alpha x)\right] \\
\frac{d^{2} y}{d x^{2}}=2 \alpha^{2} e^{-\alpha x}\left[C_{2} \sin (\alpha x)-C_{1} \cos (\alpha x)\right]=-\frac{M}{E I} \\
\frac{d^{3} y}{d x^{3}}=-2 \alpha^{3} e^{-\alpha x}\left[\left(C_{2}-C_{1}\right) \sin (\alpha x)-\left(C_{1}+C_{2}\right) \cos (\alpha x)\right]=-\frac{Q}{E I}
\end{gathered}
$$

According to the theory of elasticity, the bending moment $M_{0}$ and shear stress $Q_{0}$ of the key stratum beam at the rib in Figure 3 are:

$$
M_{0}=(0.5 x+L) q L ; Q_{0}=(0.5 x+L) q
$$

Substituting $M_{0}$ and $Q_{0}$ into Equations (7) and (8), the results are:

$$
C_{1}=\frac{M_{0}}{2 \alpha^{2} E I} ; C_{2}=-\frac{\alpha M_{0}+Q_{0}}{2 \alpha^{3} E I}
$$

Taking Equation (10) into Equation (6), the deflection deformation equation of the key stratum of the roof is:

$$
\mathrm{y}=\frac{e^{-a x} M_{0}}{2 a^{2} E I}\left[\sin (\alpha x)-\cos (\alpha x)-\frac{1}{\alpha L} \cos (\alpha x)\right]
$$

The maximum bending moment $M_{\max }$ of the key beam in the main roof and the distance $\mathrm{x}$ ahead of the rib are:

$$
\begin{gathered}
M_{\max }=e^{-\alpha x} M_{0}\left[\cos (\alpha x)+\sin (\alpha x)+\frac{3}{4 L} \sin (\alpha x)\right] \\
x=\frac{1}{\alpha} \arctan \left(\frac{2}{3 \alpha L+2}\right)
\end{gathered}
$$

where $x$ is the maximum bending moment position of the rock beam in the key stratum of the roof (the distance of rib advanced breaking), $\mathrm{m}$.

According to the maximum tensile stress criterion, the judgment conditions for the breaking of the rock stratum in the key stratum of the main roof are:

$$
\begin{gathered}
\frac{M_{\max } y}{I} \geq R_{t} \\
\frac{3(2 L+x)}{h^{2}} e^{-\alpha x}\left[\cos (\alpha x)+\sin (\alpha x)+\frac{3}{4 L \alpha} \sin (\alpha x)\right] \geq R_{t}
\end{gathered}
$$

where $L$ is the overhang distance of the key strata, $\mathrm{m} ; x$ is the leading breaking distance of the key stratum, $\mathrm{m} ; q$ is the load of the overlying strata on the key strata, MPa; $h$ is the thickness of the key strata, $\mathrm{m} ; R_{t}$ is key strata tensile strength, MPa.

\subsection{Mechanical Model of EIR Advanced Breaking Position}

During the advancement of the working face, it is necessary to provide a certain initial force through the support to control the movement of the immediate roof. The coal seam is used as the elastic foundation; the EIR is regarded as the elastic foundation beam located on the coal seam. The mechanical model of the EIR elastic foundation beam is established as shown in Figure 4. The EIR deflection and coal seam load under the supporting force of the support can be simplified by using the semi-infinite load beam theory. 


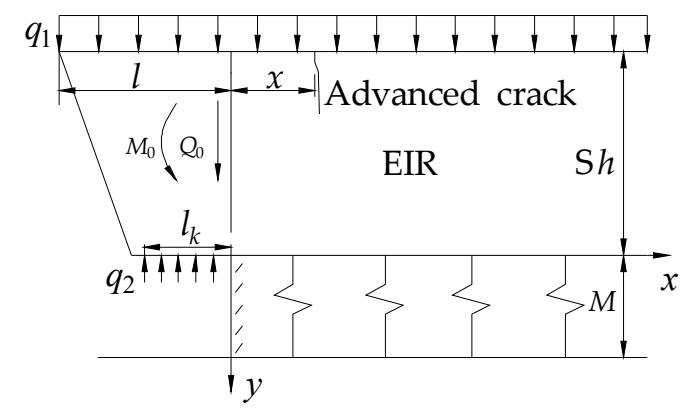

Figure 4. Mechanical model of EIR elastic foundation beam and the EIR suspension elongation is $l$.

In Figure 4, the EIR suspension elongation is $l$, and the length of the support roof beam is $l_{k}$. The bending moment $\left(M_{0}\right)$ and shear stress $\left(Q_{0}\right)$ of EIR above coal wall in working face. The mining height of coal seam $(M)$ and the height of EIR $(\Sigma h)$ as elastic foundations, the load of EIR is $q_{1}$, the support strength of the support is $q_{2}$.

According to the actual measurement [19-21], it is generally $1.5-2$ times $l_{k}\left(l_{k}\right.$ is the length of the roof beam of the support). To ensure safety, take the $l=2 l_{k}$, it can be obtained the $M_{0}$ and $Q_{0}$ at the coal wall $(x=0)$ are:

$$
\begin{gathered}
M_{0}=l_{k} \cdot\left(q_{1}-q_{2}\right) \cdot \frac{l_{k}}{2}+\left(l-l_{k}\right) \cdot q_{1}\left(l_{k}+\frac{l-l_{k}}{2}\right)=\frac{l_{k}^{2}}{2}\left(4 q_{1}-q_{2}\right) \\
Q_{0}=l_{k}\left(2 q_{1}-q_{2}\right)
\end{gathered}
$$

where $q_{1}$ is the load of EIR, $\mathrm{MPa} ; q_{2}$ is the support strength of the support, $\mathrm{MPa}$; $l_{k}$ is the length of the support roof beam, $\mathrm{m}$.

Substituting Equations (16) and (17) and related parameters of EIR into Equations (7) and (8), we get:

$$
C_{1}=\frac{M_{0}}{2 \alpha^{2} E I} ; C_{2}=-\frac{Q_{0} / \alpha+M_{0}}{2 \alpha^{2} E I} ; \alpha_{1}=\sqrt[4]{\frac{k}{4 E_{1} I_{1}}} ; \mathrm{k}_{m}=\frac{E_{m}}{M}
$$

where $E_{1}$ is the EIR elastic modulus, MPa; $I_{1}=h^{3} / 12$ is the EIR inertia moment, $\mathrm{m}^{4} ; k_{m}$ is the elastic foundation coefficient of the coal seam.

Substituting Equation (18) into Equations (6) and (7), the EIR deflection $y^{\prime}, M_{x}$, and $Q_{x}$ equations can be obtained:

$$
\begin{gathered}
y^{\prime}=\frac{e^{-\alpha x}}{2 \alpha^{2} E I}\left[M_{0} \sin (\alpha x)-M_{0} \cos (\alpha x)-\frac{Q_{0}}{\alpha} \cos (\alpha x)\right]+\frac{q_{1}}{k} \\
M_{x}=e^{-\alpha x}\left[M_{0} \cos (\alpha x)+M_{0} \sin (\alpha x)+\frac{Q_{0}}{\alpha} \sin (\alpha x)\right] \\
Q_{0}=-e^{-\alpha x}\left[Q_{0} \sin (\alpha x)+2 \alpha M_{0} \sin (\alpha x)+Q_{0} \cos (\alpha x)\right]
\end{gathered}
$$

The deformation of $q_{1} / k_{m}$ has already occurred when the working face excavated, so it can be ignored. Both sides of the Equation (19) multiplying $k_{m}$, according to the elastic foundation beam theoretical, the EIR load on the coal seam is:

$$
p=2 \alpha^{2} e^{-\alpha x}\left[M_{0} \sin (\alpha x)-M_{0} \cos (\alpha x)-\frac{Q_{0}}{\alpha} \cos (\alpha x)\right]
$$

Equation (20) shows the maximum bending moment in the EIR occurs at $Q_{x}=0$, the EIR advances the coal wall breaking distance $\left(x^{\prime}\right)$ is:

$$
x^{\prime}=\frac{1}{\alpha} \arctan \left(\frac{Q_{0}}{Q_{0}+2 \alpha M_{0}}\right)
$$


Substituting $x^{\prime}$ into Equation (20), the maximum bending moment equation is:

$$
M_{\max }=e^{-a x^{\prime}}\left[\cos \left(\alpha x^{\prime}\right)+\sin \left(\alpha x^{\prime}\right)+\frac{Q_{0}}{M_{0} \alpha} \sin \alpha x^{\prime}\right]
$$

Maximum bending stress of equivalent direct overhanging beam:

$$
\sigma_{\max }=M_{\max } / Z
$$

In the equation, $\mathrm{Z}=b^{\prime} \Sigma h^{2} / 6$ is the section coefficient.

The width $b^{\prime}=1 \mathrm{~m}$ in this model, then

$$
Z=\Sigma h^{2} / 6
$$

Substituting Equation (26) into Equation (25), the equivalent maximum direct tensile stress is:

$$
\sigma_{\max }=6 M_{\max } / \Sigma h^{2}
$$

The maximum tensile stress at the upper end of the equivalent direct overhanging beam exceeds the ultimate tensile stress.

$$
\begin{gathered}
\sigma_{\max }=6 M_{\max } / \Sigma h^{2} \geq \sigma_{\mathrm{t}} \\
M_{\max } \geq \sigma_{\mathrm{t}} \Sigma h^{2} / 6
\end{gathered}
$$

where $\sigma_{\mathrm{t}}$ is the uniaxial tensile strength of the EIR rock formation, MPa.

Substituting $M_{\max }$ into Equation (29), we can obtain the EIR rock strata fracture discriminant equation:

$$
\frac{6 e^{-\alpha x} M_{0}}{\sum h^{2}}\left[\cos \alpha x^{\prime}+\sin \alpha x^{\prime}+\frac{Q_{0}}{M_{0} \alpha} \sin \alpha x^{\prime}\right] \geq \sigma_{t}
$$

The Equation (30) shows that the stability of the EIR cantilever beam structure of the large mining height working face is not only related to its size, weight, and properties, but also affected by its upper load and support force of the bracket.

\section{Field Measurement Method}

The 22201 working face is the first ever performed in the 2-2 coal seam in the Zhangiamao Coal Mine. The average buried depth of the 2-2 coal seam is about $95 \mathrm{~m}$, the mining height is $6 \mathrm{~m}$, and the hydraulic support model is ZY12000/28/63D. In the middle of the 22201 working face, the cores are drilled to the roof coal and overlying strata mainly measured the compressive strength, tensile strength, elastic modulus, and Poisson's ratio of coal rock mass, experimental results, as shown in Table 2 [32].

Table 2. The parameters of coal and roof of no. 22201 working face.

\begin{tabular}{ccccc}
\hline Lithology & $\begin{array}{c}\text { Compressive } \\
\text { Strength } \mathbf{( M P a )}\end{array}$ & $\begin{array}{c}\text { Elastic Modulus } \\
\times \mathbf{1 0}^{\mathbf{4}} \mathbf{( M P a )}\end{array}$ & Poisson's Ratio & Cohesion (MPa) \\
\hline Coal & 35.57 & 2827 & 0.19 & $/$ \\
Coarse sandstone & 18.94 & 2217 & 0.22 & 1.40 \\
Muddy siltstone & 39.04 & 7588 & 0.14 & 4.95 \\
Mudstone & 31.57 & 2956 & 0.19 & 4.29 \\
Carbonaceous mudstone & 19.79 & 2618 & 0.21 & 2.60 \\
Siltstone & 22.16 & 2901 & 0.20 & 2.79 \\
Weathered siltstone & 12.27 & 3729 & 0.18 & 1.75 \\
\hline
\end{tabular}

In order to observe the whole process of roof advanced breaking position of the 22201 working face in mining. Three observing stations were fixed along the auxiliary headgate gateway (AHG) and headgate gateway (HG), three stations are located in $37 \mathrm{~m}, 67 \mathrm{~m}$, and $97 \mathrm{~m}$ in front of the setup 
entry. Every observed station is including three drilling holes, which are drilled into the roof as shown in Figure 5a. By the drilling peep and the mechanical multi-point displacement meter, the breaking position of the roof is observed [32].

According to the drilling angle of every drill as shown in Figure 5b, the broken position of any point in space, the roof with horizon of broken location and the suspension distance with AHG can be calculated.

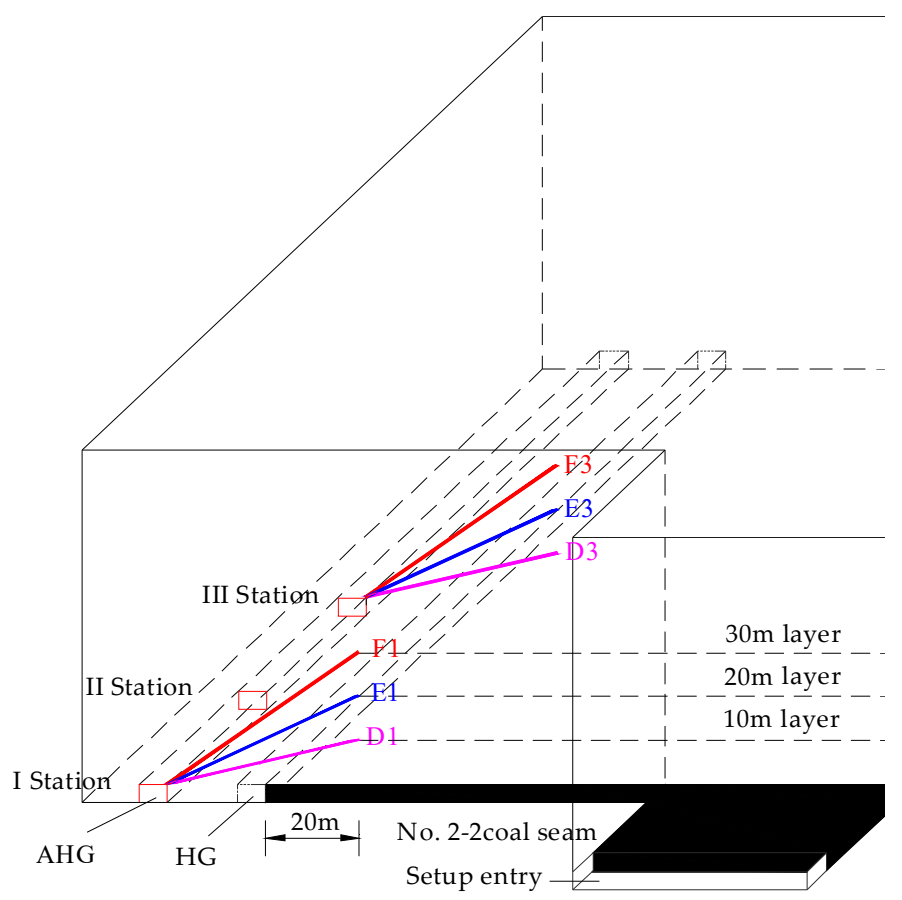

(a)

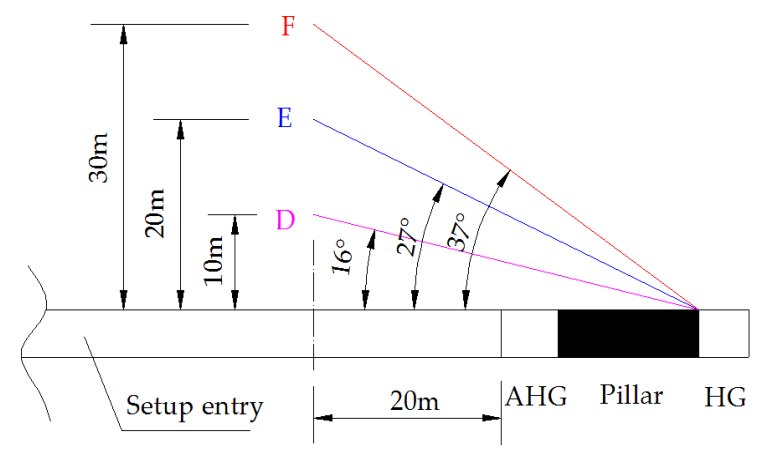

(b)

Figure 5. Schematic diagram of drilling: (a) spatial distribution map; (b) Sectional view along the working face.

\section{Results}

\subsection{Calculation Results of the Theoretical Model}

(1) Calculation Result of Key Strata Fracture

Combined with the background of the 22201 working face, the thickness of the main roof key layer $h=13 \mathrm{~m}$, the elastic modulus $E=3090 \mathrm{MPa}$, the tensile strength of the key strata $R_{\mathrm{t}}=1.14 \mathrm{MPa}$, overburden load $q=1.22 \mathrm{MPa}$. EIR thickness $\Sigma h=16 \mathrm{~m}, E_{1}=2217 \mathrm{MPa}$, average bulk density of bedrock $\gamma=24 \mathrm{kN} / \mathrm{m}^{3}$. The thickness of coal seam $M=6 \mathrm{~m}$, coal body elastic modulus $E_{\mathrm{m}}=2827 \mathrm{MPa}$, working face adopts DBT (Deutsche Bergbau Technik) shielded hydraulic support, support control 
roof distance $l_{k}=5.6 \mathrm{~m}$, support strength $q_{2}=0.9 \mathrm{MPa}$, initial support force $7916 \mathrm{kN}$, rated working resistance is $12,000 \mathrm{kN}$.

According to Equation (3), the elastic foundation coefficient of the key stratum of the roof is:

Substituting $I=h^{3} / 12$ and related parameters into Equation (3), $\alpha$ can be calculated:

$$
\alpha=\sqrt[4]{\frac{k}{4 E I}}=0.083
$$

Based on the field measurements [28], the average overhang distance of the key strata $L=6-8 \mathrm{~m}$, the range of $x$ can be obtained from Equation (13):

$$
x=5.6-6.9 \mathrm{~m}
$$

Substituting parameters $x=5.6 \mathrm{~m}$ into Equation (15), we get 6.44 MPa > 1.14 MPa; when $x=6.9$, we get $3.06 \mathrm{MPa}>1.14 \mathrm{MPa}$. Results indicate that the leading layer of the main roof has broken in advance during the working face, the distance in advance is $5.6-6.9 \mathrm{~m}$.

(2) Calculation Result of EIR Fracture

The elastic foundation coefficient of the coal seam is:

$$
k_{m}=\frac{E_{m}}{M}=471 \mathrm{MN} / \mathrm{m}^{2}
$$

Substituting $I_{1}=h_{1}{ }^{3} / 12$ and related parameters into Equation (18) can be obtained:

$$
\alpha_{1}=\sqrt[4]{\frac{k}{4 E_{1} I_{1}}}=0.112
$$

The overburden strata acts on the EIR load $q_{1}=0.85 \mathrm{MPa}$, the support loads the roof load of 0.9 $\mathrm{MPa}$, so the $x^{\prime}$ can be obtained from Equation (23).

$$
x^{\prime}=\frac{1}{\alpha} \arctan \left(\frac{Q_{0}}{Q_{0}+2 \alpha M_{0}}\right)=3.0 \mathrm{~m}
$$

The calculations show that the main roof and the EIR of the high-mining working face have advanced fracture phenomena in shallow coal seam. The theoretical calculation of key strata results $(5.6-6.9 \mathrm{~m})$ are in the range of field measurement results (5-8 m).

\subsection{Field Measurement Results}

(1) First Caving of the Main Roof

When the working face advanced to $32 \mathrm{~m}$, the main roof occurred first weighting, the first station located $5 \mathrm{~m}$ in front of the rib is not obviously broken. However, obvious movement (about $0.8 \mathrm{~m}$ displacement) was measured on the roof of the horizon of $0-10 \mathrm{~m}$, which indicates the movement of roof strata was ahead of the mining working face weighting, as shown in Figure 6. 


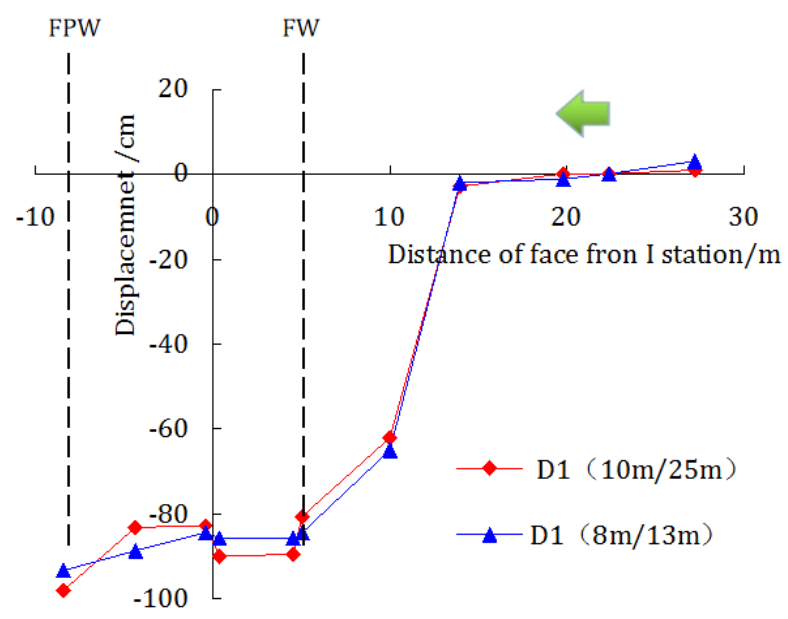

Figure 6. On-site drilling design.

Based on the actual measurement, the position of roof broken is $5 \mathrm{~m}$ ahead of the rib for the first weighting. The height of the caving zone is $10 \mathrm{~m}$, and the hinged roof is the original bedrock on the horizon of 10-20 m. According to [1], combined with the above-mentioned measured parameters, the formation of the roof "asymmetric three-hinged arch" structure during the first caving of the main roof is shown in Figure 7.

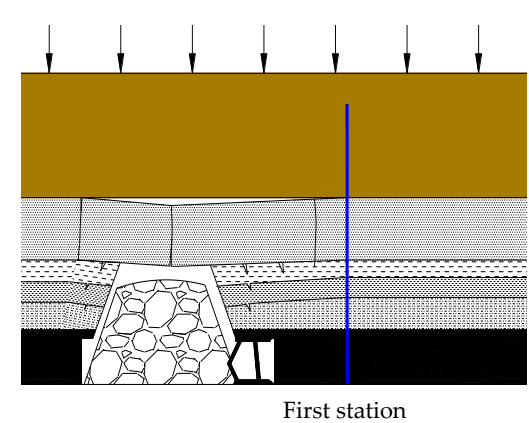

(a)

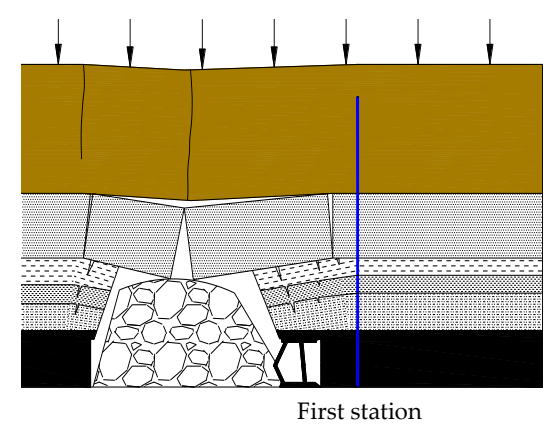

(b)

Figure 7. Sketch-profiles of the first caving showing roof structure: (a) before the first weighting; (b) after the first weighting.

(2) Periodic Caving of the Main Roof

From the observation results of the first station (located in $37 \mathrm{~m}$ in front of the setup entry), as the working face advanced to $36 \mathrm{~m}$, the roof with horizon of $24.4 \mathrm{~m}$ (suspension distance is $19 \mathrm{~m}$ ) was broken, as shown in Figure 8a. As the face advanced to $45.4 \mathrm{~m}$, behind the rib of the working face, the roof with horizon of $22.1 \mathrm{~m}$ (suspension distance is $15 \mathrm{~m}$ ) was fractured, as shown in Figure 8b. Based on the observation results of the second station (located in $67 \mathrm{~m}$ in front of the setup entry), as the working face advanced to $59 \mathrm{~m}$, the roof with horizon of $29 \mathrm{~m}$ (suspension distance is $25 \mathrm{~m}$ ) was broken as shown in Figure 8c. As the face advanced to $75 \mathrm{~m}$, behind the rib of the working face, the roof with horizon of $19 \mathrm{~m}$ (suspension distance is $12 \mathrm{~m}$ ) was fractured, as shown in Figure 8d. 


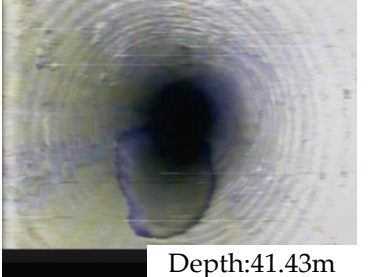

(a)

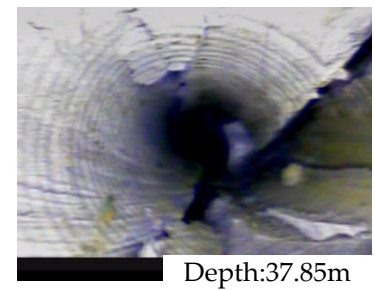

(b)

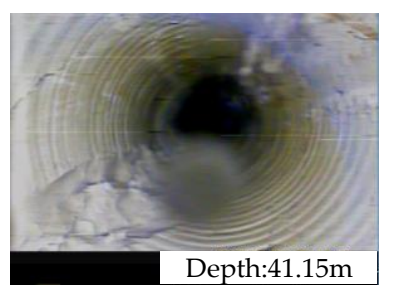

(c)

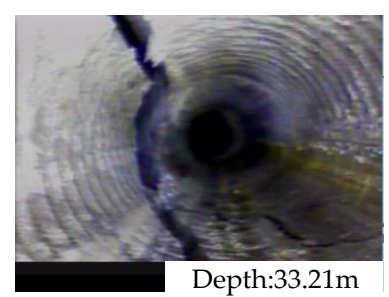

(d)

Figure 8. Drilling peep results of the station: (a) and (b) are results of the first station; (c) and (d) are results of the second station.

In the same way, when the main roof is first period caving, the roof is broken at 5-8 $\mathrm{m}$ ahead of the rib, and the roof with horizon of 16-20 m, as shown in Figure 9a. When the main roof is second period caving, a large crack occurred at the roof with horizon of $25 \mathrm{~m}$ and by $5-8 \mathrm{~m}$ ahead of the rib, as shown in Figure $9 \mathrm{~b}$. It shows that from the first weighting to the periodic weighting, the hinged level of the roof plate gradually moved from $10-20 \mathrm{~m}$ to $16-30 \mathrm{~m}$. During the period weighting, the height of the caving zone is about $16 \mathrm{~m}$, the roof hinge layer is at the level of $16-30 \mathrm{~m}$, the periodical weighting interval is $13 \mathrm{~m}$. The main roof is broken to form a periodic step rock beam structure, and the periodic step is $1.7 \mathrm{~m}$.

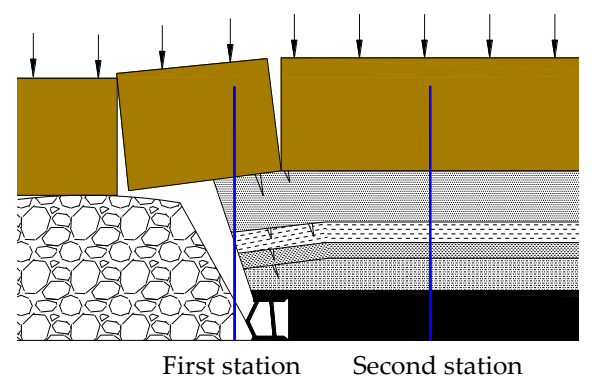

(a)

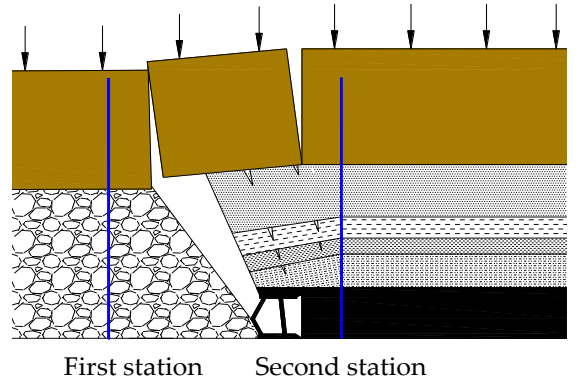

(b)

Figure 9. Sketch-profiles showing roof structure at different period weighting: (a) after the first period weighting; (b) after the second period weighting.

\subsection{The "Space-Time" Relationship between the Roof Structure Movement and Ground Pressure}

The results of roof advanced breaking position obtained from the displacement and the drilling peep of the roof in the AHG, which can explain the "space-time" relationship between the roof structure formed by the periodic breaking and the ground pressure.

(1) Before weighting: as the working face advances, the main roof bends at the 5-8 m ahead of coal wall, and the main roof reaches the limit state, also obvious cracks are observed in the drilling results. Meanwhile, the EIR has not broken; the EIR can support the main roof. The working face is not weighting, and the main roof remains stable, as shown in Figure 10a.

(2) Starting weighting: when the working face advances to 2-4 $\mathrm{m}$ from the advanced breaking line, the main roof structure $M$ block starts to rotate, and the advanced breaking line extends downward to the EIR, so the stability of the immediate roof reduced. The same time, the support capacity of the structure and the stability of the roof structure are reduced, and the pressure of the support on the measured in the 22201 working face rises and starts to come [32], as shown in Figure 10b.

(3) Coming time: when the working face is advanced near the advanced breaking line of the main roof, the main roof fracture intensifies and a large turning subsidence occurs (the angle of rotation is about $8^{\circ}$ ), which is EIR internal crack expansion. Therefore, the stability of the main roof structure reduces, the dynamic load increases, and the main roof structure sinks into steps, which cause the working surface to be pressed, as shown in Figure 10c. 
(4) After weighting: when the working face is advanced about 4-6 $\mathrm{m}$ across the break line position, the supporting face of the working face enters into the new overhang EIR, the ground pressure decreases, and the weighting of working face comes to an end. At this moment, the post-frame fractured main roof rock block slipped onto the falling goaf. Due to the mining height of EIR is $17 \mathrm{~m}$, there is about $1.7 \mathrm{~m}$ of unfilled space, as shown in Figure 10d.

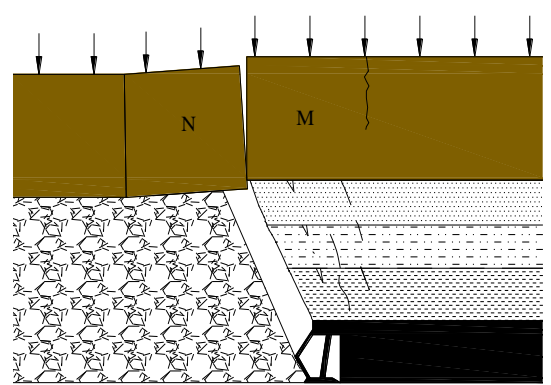

(a)

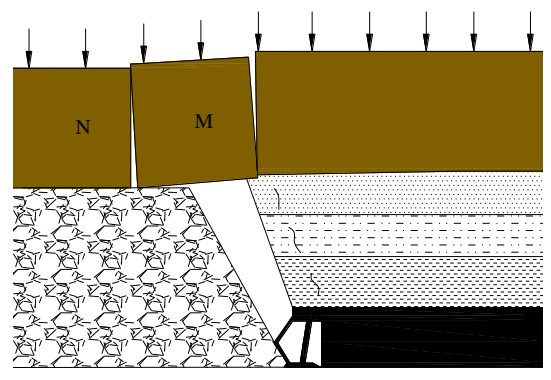

(c)

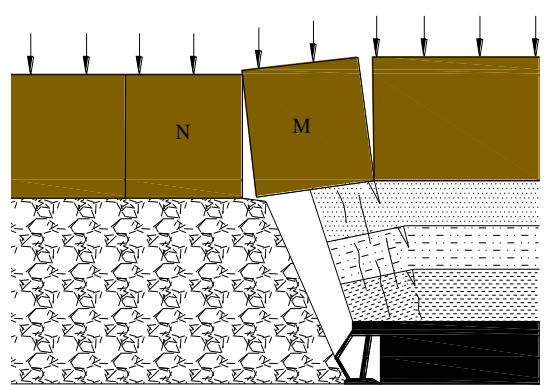

(b)

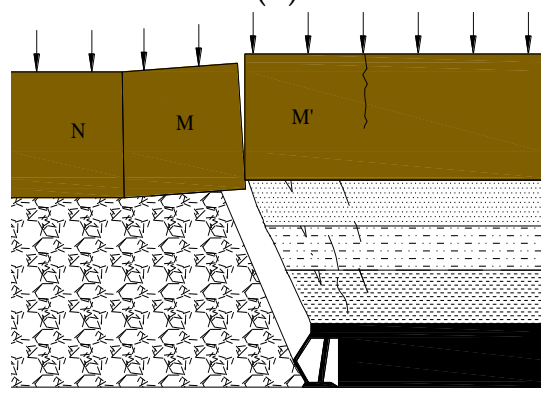

(d)

Figure 10. Structural evolution process of "step rock beam" in shallow buried large mining height: (a) before weighting; (b) starting weighting; (c) weighting time; (d) after weighting.

\subsection{The Relationship between Filling Rate of EIR and Roof Structure}

Due to the different mining heights, different thicknesses of EIR will be formed, and the extent of filling of the goaf will also be different. Different advance breaking positions will cause different loads above the support; it will lead to different roof structure and ground pressure.

According to Figure 11, the height of the interspace between the EIR and the main roof is:

$$
\Delta=M+\Sigma h_{i}-h_{c}
$$

where $h_{c}$ is the filling height of EIR, $\mathrm{m} ; \Sigma h_{i}$ is the thickness of EIR, $\mathrm{m} ; M$ is the mining height, $\mathrm{m}$.

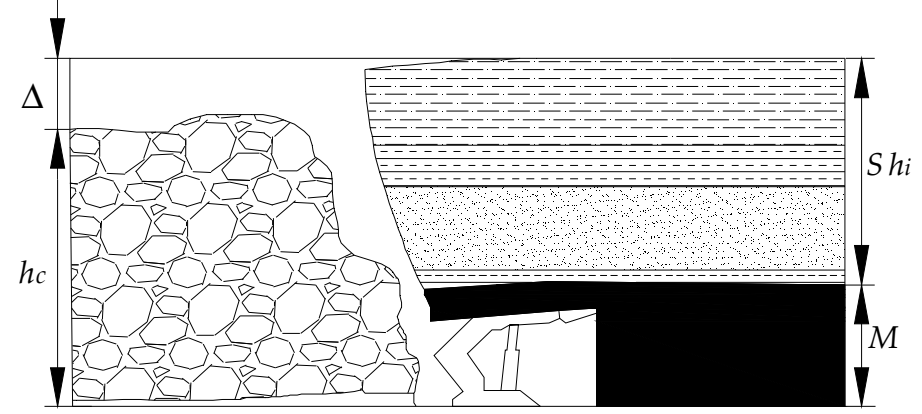

Figure 11. Sketch-profile evidencing variations in the relationship between $k_{p}, k_{i}$ and filling rate.

The fill rate of the EIR is:

$$
\delta=\frac{h_{c}}{\Sigma h_{i}+M} \times 100 \%
$$


where $\delta$ is the EIR filling rate, \%.

The filling height of the EIR collapse is:

$$
h_{\mathrm{c}}=K_{p} \Sigma h_{i}
$$

Then, the thickness of EIR and mining height ratio is

$$
k_{i}=\Sigma h_{i} / M
$$

Substituting Equations (33) and (34) into Equation (32), we can get:

$$
\delta=\frac{k_{p} k_{i}}{k_{i}+1} \times 100 \%
$$

According to Equation (35), if the $k_{\mathrm{p}}$ is constant, when the $k_{i}$ increases, the fill rate also increases. The changing relationship between $k_{p}, k_{i}$ and filling rate shown in Figure 12.

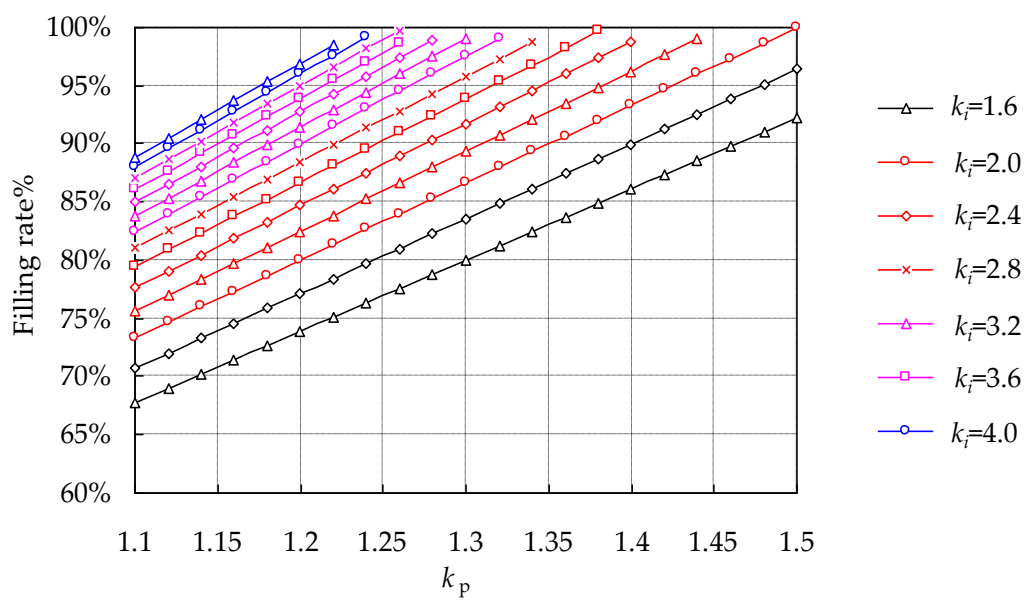

Figure 12. $K_{p}$ vs. Filling-rate $\%$ variation diagram for different $k_{i}$.

\section{Conclusions}

(1) Based on the theory of the "elastic foundation beam", mechanical models for the key strata and EIR advanced breaking position of large mining height working face in shallow coal seam are established. According to the field measured physical and mechanical parameters of the $22201 \mathrm{LMH}$ working face, the theoretical calculation of key strata results $(5.6-6.9 \mathrm{~m})$ are in the range of field measurement results $(5-8 \mathrm{~m})$.

(2) In mining practice, the roof with horizon of $0-10 \mathrm{~m}$ has detected advanced movement displacement in the $22201 \mathrm{LMH}$ working face. It is shown that the advanced breaking of the LMH working face in shallow coal seam can be used as an indication of roof weighting, providing early warning for the site of large-mining work face, and ensuring the safety of the mining.

(3) Under the condition of different filling rates, different EIR have different filling degrees of goaf. The degree of filling in the goaf determines the shape and stability of the main roof structure of the stope in shallow coal seam. Different roof structures will lead to different degrees of weighting.

Author Contributions: Conceptualization, Q.H.; Experimental Design, Q.H.; Y.H., and F.L.; Validation, Q.H. and Y.H.; Data Curation, Y.H. and F.L.; Supervision, Q.H.; Writing-Original Draft Preparation, Y.H. and F.L.; Writing-Review \& Editing, Q.H. and Y.H.; Supervision, Q.H.; Project Administration, Q.H.; Funding Acquisition, Q.H. All authors have read and agreed to the published version of the manuscript.

Funding: This research was funded by the National Natural Science Foundation of China, grant number No.51674190 and No. 51174278. Natural Science Basic Research Program of Shaanxi, program No.2019JLP-08. 2019 Excellent Doctoral Dissertation Program of University, program No.PY19001. 
Acknowledgments: We thank the National Natural Science Foundation of China and Natural Science Basic Research Program of Shaanxi for its support of this study. We thank the academic editors and anonymous reviewers for their kind suggestions and valuable comments.

Conflicts of Interest: The authors declare no conflict of interest.

\section{References}

1. Huang, Q.X. Study on Roof Structure and Ground Control in Shallow Seam Longwall Mining; China University of Mining and Technology press: Xuzhou, China, 2000.

2. Wang, S.M.; Huang, Q.X.; Fan, L.M.; Wang, W.K. The Key Technology of Water Conservation Mining in Fragile Ecologically Mining Coal Resources; Science Press: Beijing, China, 2010.

3. Qian, M.G.; Shi, P.W.; Xu, J.L. Coal Mine Pressure and Strata Control; China University of Mining and Technology Press: Xuzhou, China, 2010.

4. $\quad$ Peng, S.S.; Chiange, H.S. Longwall Mining; Wiley: New York, NY, USA, 1984.

5. Mahdi, S.; Charlie, C.L. Numerical modelling of longwall mining and stability analysis of the gates in a coal mine. Int. J. Rock Mech. Min. Sci. 2012, 51, 24-34.

6. Ghosh, G.K.; Sivakumar, C. Application of underground microseismic monitoring for ground failure and secure longwall coal mining operation: A case study in an Indian mine. J. Appl. Geophys. 2018, 150, 21-39. [CrossRef]

7. Yang, S.; Wang, J.; Li, X.H.; Ning, J.G.; Qiu, P.Q. In situ investigations into mining-induced hard main roof fracture in longwall mining: A case study. Eng. Fail. Anal. 2019, 106, 104188. [CrossRef]

8. Liu, S.Y.; Qian, M.G. The numerical analysis of the cracked position and inclination of the main roof. J. China Univ. Min. Techno. 1989, 18, 31-36.

9. Sofianos, A.I. Analysis and design of underground hard rock voussoir beam roof. Int. J. Rock Mech. Min. Sci. 1996, 33, 153-166. [CrossRef]

10. Huang, Q.X.; Qian, M.G.; Shi, P.W. Structural analysis of main roof stability during periodic weighting in long wall face. J. China Coal Soc. 1999, 24, 581-585.

11. Hou, Z.J. Concept of both short voussoir beam and step beam in shallow seam and voussoir beam theory. J. China Coal Soc. 2008, 33, 1201-1204.

12. Huang, Q.X. Experimental research of overburden movement and subsurface water seeping in shallow seam mining. J. Univ. Sci. Tech. Beijing 2007, 14, 483-489. [CrossRef]

13. Holla, L.; Buizen, M. Strata Movement Due to Shallow Longwall Mining and the Effect on Ground Permeability. Proc. Aust. IMM 1990, 295, 11-18.

14. Singh, K.B.; Kumar, P.; Kiran, S.; Saxena, N.C.; Singh, B. Subsidence behavior of Motur clays. J. Mines Met Fuels. 1992, 2, 93-100.

15. Maleki, H. Coal pillar mechanics of violent failure in U.S. Mines. Int. J. Min. Sci. Technol. 2017, 27, 387-392. [CrossRef]

16. Huang, Q.X.; He, Y.P.; Cao, J. Experimental investigation on crack development characteristics in shallow coal seam mining in China. Energies 2019, 12, 1302. [CrossRef]

17. Wang, S.R.; Wu, X.G.; Zhao, Y.H.; Hagan, P.; Cao, C. Evolution characteristics of composite pressure-arch in thin bedrock of overlying strata during shallow coal mining. Int. J. Appl. Mech. 2019, 11, 1-16. [CrossRef]

18. Zhang, Z.Q.; Xu, J.L.; Liu, H.L.; Li, H.W. Influencing laws study of depth of gully on dynamic strata pressure of working face in shallow coal seams. J. Min. Saf. Eng. 2013, 30, 501-505.

19. Huang, Q.X.; Zhou, J.L. Roof weighting behavior and roof structure of large mining height longwall face in shallow coal seam. J. China Coal Soc. 2016, 41, 279-286.

20. Huang, Q.X.; Zhou, J.L.; Ma, L.T.; Tang, P.F. Double key stratum structure analysis of large mining height longwall face in nearly shallow coal seam. J. China Coal Soc. 2017, 42, 2504-2510.

21. Huang, Q.X.; Tang, P.F. Roof structure analysis on large mining height longwall face in shallow coal seam. J. Min. Saf. Eng. 2017, 34, 282-286.

22. Gong, P.L.; Jin, Z.M. Study on the structure characteristics and movement laws of overlying strata with large mining height. J. China Coal Soc. 2004, 29, 7-12.

23. Gong, P.L.; Jin, Z.M. Mechanical model study on roof control for fully-mechanized coal face with large mining height. Chin. J. Rock Mech. Eng. 2008, 27, 193-198. 
24. Xu, J.L.; Ju, J.F. Structural morphology of key stratum and its influence on strata behaviors in fully-mechanized face with super-large mining height. Chin. J. Rock Mech. Eng. 2011, 30, 1547-1556.

25. Xu, J.L.; Zhu, W.B.; W, X.Z.; Yi, M.S. Classification of key stratum structure of overlying strata in shallow coal seam. J. China Coal Soc. 2009, 34, 865-870.

26. Ju, J.F.; Xu, J.L.; Zhu, W.B. Longwall chock sudden closure incident below coal pillar of adjacent upper mined coal seam under shallow cover in the Shendong coalfield. Int. J. Rock Mech. Min. Sci. 2015, 77, 192-201. [CrossRef]

27. Yan, S.H.; Yin, X.W.; Xu, H.J.; Xu, G.; Liu, Q.M. Roof structure of short cantilever-articulated rock beam and calculation of support resistance in full-mechanized face with large ming height. J. China Coal Soc. 2011, 36, 1816-1820.

28. Wang, F.T.; Duan, C.H.; Tu, S.H.; Liang, N.N.; Bai, Q.S. Hydraulic support crushed mechanism for the shallow seam mining face under the roadway pillars of room mining goaf. Int. J. Min. Sci. Eng. 2017, 27, 853-860. [CrossRef]

29. Yuan, Y.; Tu, S.H.; Zhang, X.; Li, B. System dynamics model of the support- surrounding rock system in fully mechanized mining with large mining height face and its application. Int. J. Min. Sci. Tec. 2013, 23, 879-884. [CrossRef]

30. Liu, C.Y.; Li, H.M.; Mitri, H.; Jiang, D.J.; Li, H.G.; Feng, J.F. Voussoir beam model for lower strong roof strata movement in longwall mining-Case study. J. Rock. Mech. Geo. Eng. 2017, 9, 1171-1176. [CrossRef]

31. Li, H.M.; Jiang, D.J.; Li, D.Y. Analysis of ground pressure and roof movement in fully- mechanized top coal caving with large mining height in ultra-thick seam. J. China Coal Soc. 2014, 39, 1956-1960.

32. Huang, Q.X.; He, Y.P. Research on overburden movement characteristics of large mining height working face in shallow buried thin bedrock. Energies 2019, 12, 4208. [CrossRef]

33. Huang, Q.X. Study on loading distribution law on key roof and its structure upon mining face under thick sandy horizon. J. China Univ. Min. Technol. 2005, 34, 289-293.

34. Huang, Q.X. Ground pressure behavior and definition of shallow seams. Chin. J. Rock Mech. Eng. 2002, 21, 1174-1177.

35. Huang, Q.X.; Zhang, P. Study on dynamic load distribution on key roof blocks. Chin. J. Rock Mech. Eng. 2004, 24, 4179-4182. 